\title{
A PROPÓSITO DEL PROCESO, LA DEMOCRACIA PARTICIPATIVA Y EL ROL DE LOS MEDIOS DE COMUNICACIÓN
}

\begin{abstract}
ALESSANDRO SOMMA*
Resumen

El diálogo social es un componente indispensable del orden democrático; de ahí que se analice la importancia del nexo entre, de un lado, la libertad y el pluralismo de la información y, del otro, la autonomía de la magistratura; ambos al servicio de un diálogo social productivo de participación democrática en la cuestión procesal. El derecho a la información es el derecho a entender, no solo bajo la perspectiva liberal tradicional, sino bajo la perspectiva radicada en el texto constitucional; es decir, el derecho a la información es un instrumento para asegurar la participación de los ciudadanos en la gestión de la cosa pública; derecho que está dirigido a garantizar la protección del individuo frente al poder.
\end{abstract}

Palabras clave: Diálogo social - Medios de comunicación - Derecho a la información - Constitución - Autonomía de la magistratura - Proceso Democracia participativa.

\begin{abstract}
Social dialogue is an essential component of democracy and therefore the importance of the link between freedom and pluralism of information on the one hand and the autonomy of the judiciary on the other: both at the service of a productive social dialogue of democratic participation in procedural issues must be analyzed. The right to information is the right to understand, not only under the traditional liberal viewpoint but under the perspective rooted in the constitution, that is, the right to information is an instrument to ensure participation of citizens in the management of public interest, a right that is designed to guarantee the protection of individuals in the face of power.
\end{abstract}

Key words: Social dialogue - Media - Right to Information - Constitution Autonomy of the Judiciary - Process - Participative Democracy.

\footnotetext{
Alessandro Somma, actualmente Profesor ordinario de Derecho Comparado de la Universitá degli Studi di Ferrara (Italia), Delegado del Rector para el Área Internacional de dicha Universidad, ha sido investigador del Max-Planck-Institut für Europäische Rechtsgeschichte di Francoforte, y ha dictado diversas conferencias sobre dicha materia. Traducción a cargo de: Yuri Tornero Cruzatt quien sigue actualmente el doctorado en Comparación Jurídica e Histórico Jurídica en la Universitá degli Studi di Ferrara (Italia) bajo la tutoría del citado autor.

El texto desarrolla una intervención del autor para el encuentro del Consejo Superior de la Magistratura "las representaciones de la Justicia", Roma, 22-24 de marzo del 2010.
} 


\title{
Alessandro Somma - A propósito del proceso, la democracia participativa y el rol de
} los medios de comunicación

\begin{abstract}
Sumario
1.- El mundo del derecho y su norteamericanización. 2.- El juez y su imagen: entre técnica, cultura y política. 3.- La lección de Gardone: tercer poder y definición del sentido político. 4.- Jueces, democracia de los trabajadores y uso alternativo del derecho. 5.- Proceso y rol del intérprete entre consciencia del juez y diálogo social. 6.- Sigue: cuándo y cómo dialogar. 7.- Proceso y medios de comunicación: las lecciones de Torino. 8.- Proceso y democracia participativa en la sociedad de la información.
\end{abstract}

\section{EL MUNDO DEL DERECHO Y SU NORTEAMERICANIZACIÓN}

Mucho se ha escrito, y no solo en la última década, sobre la denominada norteamericanización del derecho ${ }^{1}$. Con esta expresión, deplorable en cuanto comprime la riqueza cultural de un continente a favor de la experiencia nacional hegemónica, se alude a la circunstancia según la cual la producción de reglas y la organización institucional típicas del common law estadounidense constituyen el horizonte hacia el cual están dirigidas las diversas experiencias jurídicas del globo, incluyendo aquellas del civil law.

En particular, este movimiento se refiere al redimensionamiento del rol del Estado en la disciplina de las relaciones de mercado ${ }^{2}$, sector en el cual las dinámicas de la circulación de los modelos tienen poco que ver con las reconstrucciones clásicamente propuestas por los comparatistas. En efecto, la idea según la cual la circulación es inducida por el prestigio del modelo exportado resulta superada por una realidad construida por exportaciones forzadas de modelos económicos en el ámbito del actual choque entre capitalismos: el renano y el anglosajón ${ }^{3}$. Un choque, amplificado por la disolución del bloque soviético, que parece resolverse a favor del segundo tipo de capitalismo, o, de todas formas, a favor de una convergencia con los esquemas por éste propuestos. Lo anterior como consecuencia del incentivo creado por el Banco Mundial que desde hace algunos años está empeñado en acreditar los sistemas del common law como ordenamientos capaces de conducir a la construcción de un mercado mundial; objetivo que se considera obstaculizado en los sistemas del civil law, dada la impronta estatalista de estos últimos.

\footnotetext{
1 Cfr. el debate que surgió entorno al movimiento de Law and development desde los años sesenta, sintetizado, por ejemplo, en la antología de A. Carty, Law and Development, New York, 1992, pp. 3 y ss.

2 Para todos M.R. FERRARESE, Le istituzioni della globalizzazione, Boloña, 2000, pp.96 ss.

3 Ver la síntesis de M. Albert, Capitalismo contro capitalismo (1991), Bologna, 1993. A. Somma, Alemania, Europa y crisis de la deuda soberana en la economía social de mercado, en Puente@Europa, 2013, pp. 95 y ss.

4 Cfr. A. Somma, Scontro tra capitalismi, crisi del debito sovrano e diritti fondamentali, en Dir. pubbl. comp. eur., 2013, p. 451 y ss.
} 
Alessandro Somma - A propósito del proceso, la democracia participativa y el rol de los medios de comunicación

Son muchas las pruebas de este desarrollo, tanto con referencia a la producción de reglas, como en relación con la organización institucional y, entonces, con el modo de ser de las profesiones legales.

Cada vez más, la producción de las reglas tiene lugar mediante mecanismos alternativos a aquellos previstos por la democracia participativa, típicos del estado moderno en la forma que tomaron durante su reciente evolución. En este último, los preceptos son formulados en el ámbito de procesos que, por un lado, aseguran a los participantes la concreta posibilidad de incidir en su contenido $y$, por otro, son formulados en términos de imposiciones precedidas por sanciones (hard law). Actualmente, ganan espacio los preceptos formulados según las reglas de la democracia deliberativa que aseguran la mera posibilidad de tomar parte en su formulación y que son, además, expresados en términos de meros incentivos para conseguir el resultado deseado (soft law). Es decir, se asiste a un debilitamiento del carácter público de los preceptos, siempre más similares a normas convencionales, es decir, a la regla contractual ${ }^{5}$.

La dimensión publicista también pierde importancia en el ámbito de la profesión del abogado, cada vez menos estructurada bajo formas que permitan tener en cuenta su dimensión como parte esencial del momento jurisdiccional. Esto induce, al menos, a considerar la progresiva extensión de las reglas previstas para la erogación de servicios y la construcción, en el mismo ámbito, de un mercado europeo ${ }^{6}$. Reglas que, entonces, son pensadas para regular la actividad de un operador económico, más que para regular el ejercicio de funciones de naturaleza, en sentido amplio, publicista.

Como es bien sabido, también se puede hablar de americanización con referencia a la figura del juez, sobre todo en relación con el valor de los actos que resuelven las instancias de juicio más elevadas. En efecto, si en los sistemas de common law rige el vínculo del precedente judicial, en los sistemas de civil law el precedente está dotado de una autoridad de facto cada vez más semejante a aquella reconocida a las fuentes formales del derecho ${ }^{7}$.

En general, en los países de civil law se considera al juez como una institución llamada a responder a expectativas sociales, cuya importancia se identifica

5 Citaciones en A. Somma, Soft law sed law. Diritto mórbido e neocorporativismo nella costruzione dell' Europa dei mercati en ella distribuzione dell' Europa dei diritti, en Riv. Crit. Dir. Priv., 2008, pp. 437 y ss.

6 G. Alpa, L'avvocato. I nuovi volti della professione forense nell' età della globalizzazione, 2 ed., Bologna, 2008, pp.57 y ss.

7 Para todos A. Gambaro, R. Sacco, Sistemi giuridici comparati, en Trattato di diritto comparato, dir. por R. Sacco, Torino, 1996, pp. 44 y ss. 
Alessandro Somma - A propósito del proceso, la democracia participativa y el rol de los medios de comunicación

más allá del objeto de la singular controversia, resaltando su rol en cuanto poder constitucional ${ }^{8}$. Esta circunstancia, acrecentada, sobre todo, por la crisis de la política y de su capacidad para responder a las expectativas sociales ${ }^{9}$, evidencia el rastro de un acercamiento del modelo de civil law al modelo de common law.

\section{EL JUEZ Y SU IMAGEN: ENTRE TÉCNICA, CULTURA Y POLÍTICA}

Si en los países de civil law la figura del juez parece cada vez más cerca a los modelos de common law, y si lo mismo puede decirse del mundo del derecho en su totalidad, la imagen del poder judicial, más estática, sigue siendo alimentada por los poderes legislativo y ejecutivo.

En síntesis, tendencialmente, los países de common law conciben la tripartición de los poderes como la imaginaba Montesquieu, es decir, atribuyendo, a cada poder, igual dignidad y, entonces, igual capacidad de ejercitar controles recíprocos. En efecto, si es verdad que se debe a MONTESQUIEU la imagen del juez como boca de la ley, también es verdad que esta idea no contrastaba con la idea de una equiparación de los poderes estatales ${ }^{10}$ : esta idea era pensada para la sociedad de clases, dentro de la cual el poder real era equilibrado con el poder de la aristocracia.

Para los países del civil law o, mejor, para la tradición que se configuró con la revolución francesa, el poder legislativo es, más bien, un poder ubicado en una posición privilegiada respecto a los poderes ejecutivo y judicial. Esto, debido a que el poder legislativo es más cercano a la voluntad popular o, mejor, a la voluntad del yo colectivo teorizado por RoUSSEAU: solución que, para algunos, se presta a fomentar formas de despotismo de la mayoría en sustitución del despotismo del monarca ${ }^{11}$.

En la experiencia italiana, la imagen del tercer poder está ligada a la calificación de la república como sistema parlamentario monista, en el cual los poderes deben estar fundamentados en la soberanía popular, razón por la cual el principio de la separación de poderes no se eleva a valor fundamental de la

\footnotetext{
8 Por ejemplo A. Garapon, I custodi dei diritti. Giustizia e democracia (1996), Milano, 1997, pp.19 y ss.

9 Cfr. P. Davigo, I profili mediatici dell' attività giudiziaria, conferencia en el encuentro de estudio de los Consejos superiores de la magistratura "Magistratura e mass media", Roma, 3-5 de abril de 2006, p. 3 de la versión mecanográfica.

10 Recientemente P. Ridola, Preistoria, origini e vicende del costituzionalismo, en P. Carrozza, A. Di GIOvENE, G.F. FERRARI (eds.), Diritti costituzionale comparato, Roma- Bari, 2009, pp. 33 s.

11 Por ejemplo M. Fioravanti, Costituzione, Boloña, 1999, pp.118 y ss. Ver también P. Costa, Cittadinanza, RomaBari, 2005, pp. 41 y ss.
} 
Alessandro Somma - A propósito del proceso, la democracia participativa y el rol de los medios de comunicación

organización estatal. Bajo tal perspectiva, el poder legislativo, en cuanto poder más cercano a la soberanía popular, prevalece, como hemos dicho, sobre el poder ejecutivo. Si se puede hablar de una separación del poder judicial de los otros poderes, es en virtud de un principio de racionalidad, según el cual, el correcto funcionamiento de las instituciones estatales está asegurado, entre otras cosas, por la acción de un cuerpo compuesto por técnicos del derecho fuera del circuito en el que se forma la orientación política ${ }^{12}$.

Ya se ha reconocido que este enfoque debe tener en cuenta el papel asumido por las cortes como fuentes sustanciales de producción de las reglas. Es decir, se ha afirmado que la imagen del juez ya no puede reducirse a aquella de un frío burócrata que decide en nombre del yo colectivo y que, entonces, carece de un perfil en el cual se admitan espacios de autonomía expresiva. Además, el aporte del juez a la producción del derecho es considerado con una relevancia de tipo cultural, entendiendo con ello que si el aporte no es de tipo técnico, tampoco es de tipo político. En efecto, el aporte se referiría a "movimientos de pensamientos más lentos y complejos" consolidados, en un largo periodo, como orientaciones compartidas por los principales operadores del derecho, en cuanto los jueces generan posiciones en las que se sintetiza la labor de abogados y estudiosos. El poder judicial, en suma, como portador "de aquellas influencias jurídico culturales" que sustentan "la continuidad del derecho, si bien en constante evolución"13.

Así sintetizado, el rol del tercer poder sería equiparable a aquel de una fuente del derecho, pero solo en el límite de una actuación dirigida a la conservación de lo existente y, entonces, para defenderse de la contingencia política. En efecto, si se pone el acento en la legitimación otorgada por la específica cultura profesional, se termina por reducir el rol del tercer poder a guardián de aquel tecnicismo, cuya perpetuidad, según algunos, identifica el núcleo esencial de la denominada tradición jurídica occidental. Lo que equivale a un regreso a la concepción según la cual el derecho "sigue distinguiéndose de la política y de la religión, así como de los demás tipos de instituciones sociales y de las otras disciplinas" 14 .

De este modo, se termina por no liberar la imagen del juez de su vicio de fondo: relegarlo a un rol en el cual se desconoce la naturaleza exquisitamente política, un rol incompatible con su carácter de participante de la construcción

12 A. PIZZORUSSO, L' organizzazione della giustizia in Italia. La magistratura nel sistema político e istituzionale, nuova ed., Torino, 1990, pp. 61 y ss.

13 Ivi, pp. 64 y ss.

14 H. J. BERMAN, Diritto e rivoluzione. Le origini della tradizione giuridica occidentale (1983), Bologna, 1998, p. 68. 
Alessandro Somma - A propósito del proceso, la democracia participativa y el rol de los medios de comunicación

de las reglas de convivencia social en un plano paritario respecto a de los otros poderes. En suma, si, de un lado, se evita ver al juez como simple boca de la ley, de otro lado, se reduce a boca de una no mejor definida tradición profesional, ocultando, pero no resolviendo, los problemas de legitimación.

También se puede rechazar esta conclusión como propósito político normativo. Y, sin embargo, dicha conclusión parece inevitable, cuando se quiera abandonar el plano de la reconstrucción de un sistema en términos, más o menos, explícitamente prescriptivos y se pretenda, más bien, enfrentarse a un mundo jurídico hecho de normas, pero también de instituciones en conflicto entre ellas. Desde tal punto de vista es inevitable reconocer que la atribución de sentido a los textos normativos no es una operación relevante simplemente como problema hermenéutico, sino, también, y principalmente, como problema político ${ }^{15}$ : una operación relativa más al posicionamiento en el conflicto entre instituciones, que a la búsqueda de una verdad, más o menos, absoluta.

\section{LA LECCIÓN DE GARDONE: TERCER PODER Y DEFINICIÓN DEL SENTIDO POLÍTICO}

A este punto, no parece inútil recordar que, por largo tiempo, precisamente la magistratura se ha preocupado por configurar indicaciones innovadoras acerca del rol del tercer poder y acerca de su relación con aquel más cercano a la soberanía popular: el poder legislativo. Un rol quizás compatible con la idea según la cual, aquel de los jueces, constituye un aporte cultural, y no político, a la regulación de la convivencia social; siempre y cuando por cultura se entienda un conjunto de preceptos madurados en modo elitista y auto-referencial en el ámbito de un cuerpo profesional. Es decir, siempre y cuando se valorice la circunstancia según la cual, si la cultura tiene que ver con orientaciones de largo periodo, esta coincide, principalmente, con el conjunto de los valores de nivel super-primario. Y estos últimos, si no se refieren a la definición de las líneas políticas contingentes, se refieren a la definición de las líneas políticas generales; las primeras entendidas como una derivación de las segundas.

Esta visión fue desarrollada como resultado del conocido congreso de la Asociación Nacional Magistrados de GARDONE, realizado en setiembre de 1965. En ese periodo, la denominada congelación constitucional ${ }^{16}$, es decir, la

\footnotetext{
${ }_{15}$ Citaciones en A. SOMMA, Tecniche e valori nella ricerca comparatistica, Torino, 2005, pp.45 y ss.

${ }_{16}$ Por ejemplo, C. SAlvi, La giusprivatistica fra códice e scienza, en A. Schiavone (ed.), Stato e cultura giuridica in Italia dall'Unitá alla repubblica, Roma-Bari, 1990, p. 270.
} 
Alessandro Somma - A propósito del proceso, la democracia participativa y el rol de los medios de comunicación

carente ejecución de la constitución, estaba llegado a su ocaso. No obstante, aún se consideraban presentes "los graves daños causados al ciudadano derivados del formalismo y de los excesivos tecnicismos jurídicos", motivo por el cual era indispensable confirmar el rol del tercer poder como fuente del derecho ${ }^{17}$.

Como se ha recordado, también recientemente ${ }^{18}$, el congreso, ciertamente, no buscó alimentar el clima de contestación que habría caracterizado el debate acerca del rol de la magistratura en el curso de los años '70, del cual nos ocuparemos dentro de poco. Tan es así que la conferencia principal fue confiada a Giuseppe MARANINI, un liberal convencido de la superioridad del sistema constitucional típico de los países del common law, también, y sobre todo, por el rol asignado al tercer poder.

MARANINI parte de la constatación según la cual el valor principal del constitucionalismo postfascista es la protección de la "persona humana" que, como ha demostrado la historia, está amenazada cuando se verifica una "concentración de poder en una única sede". De aquí la aversión de los constituyentes italianos frente a la "dictadura de la asamblea" y la "dictadura del ejecutivo", la primera típica de la fase pre-fascista y la segunda de la época fascista. Una aversión de la cual habría derivado el favorecimiento por un sistema poli-céntrico, capaz de valorizar el nexo entre poderes y soberanía popular; pero, al mismo tiempo, capaz de impedir a cualquiera de tales poderes de acreditarse como su intérprete único o más calificado. En tal sentido, la Constitución habría creado un sistema según el cual "ningún centro de poder" adquiere "el monopolio de la determinación de la orientación política". Un sistema en el cual al tercer poder se le confía el rol de controlar que "la orientación política contingente" sea asumida respetando "la orientación política general: los objetivos de la Constitución y de todas normas con las que la Constitución se busca asegurar la persecución de sus fines $^{\prime \prime 19}$.

MARANINI no ahorra ninguna crítica contra la orientación de la magistratura y, en particular, de la Corte de Casación, cuyos jueces adherían, en ese entonces, a la Unión de Magistrados Italianos, distinta de la Asociación Nacional de Magistrados. La alta magistratura era numéricamente reducida y, sin embargo, estaba situada en una posición privilegiada que le permitía

17 Asociazione nazionale dei magistrati, Atti e commenti del $12^{\circ}$ congresso nazionale, Roma, 1996, p.8.

18 M. MARCHESIELlO, Tornare a Gardone, en Riv. trim. dir y proc. civ., 2005, pp. 1323 ss.

19 G. MARANINI, Funzione giurisdizionale ed indirizzo político nella costituzione, en Asociazione nazionale magistrati, Atti e commenti, cit., pp. 3 ss. 
Alessandro Somma - A propósito del proceso, la democracia participativa y el rol de los medios de comunicación

"obstaculizar y retardar la efectiva vigencia de los derechos de libertad consagrados en la Constitución". De este modo, el llamado a no obstaculizar "el libre contraste entre la orientación política del gobierno" y del parlamento, y "la orientación política del juez" ${ }^{20}$ estaba dirigido a los poderes legislativo y ejecutivo, pero también al vértice del poder juridicial.

De aquí la conclusión resumida en una moción que el congreso de GARDONE aprobó por aclamación: "el problema de la orientación política en el ámbito de la función jurisdiccional no se formula, obviamente, en términos de orientación política contingente, que corresponde a las fuerzas políticas titulares de la función legislativa y ejecutiva, sino en términos de tutela de la orientación política constitucional, en cuanto la constitución codificó determinadas elecciones políticas fundamentales, imponiéndolas a todos los poderes del Estado, incluyendo el judicial, y atribuyendo a este último, además del Jefe de Estado y de la Corte Constitucional, el deber de garantizar su respeto" ${ }^{\prime 21}$.

\section{JUECES, DEMOCRACIA DE LOS TRABAJADORES Y USO ALTERNATIVO DEL DERECHO}

Las reflexiones dedicadas durante los años 60's a la valorización del contenido constitucional asumieron una centralidad del todo particular en los debates inspirados por el clima de contestación de la década sucesiva. Lo anterior no debe asombrar: la oposición comunista se paseaba de la vía constitucional a la afirmación de su credo desde la época de la Constituyente, cuando se delineó la oposición togliettiana a una realización del socialismo por medio de las instituciones republicanas; opción que, en muchos aspectos, fueron desarrolladas en los debates de los años '70 ${ }^{22}$.

Por cierto, la opción togliatiana no atribuía un peso particular a la actividad de las cortes. En efecto, buscaba desarrollar las modalidades de participación de los trabajadores en la vida política del país, más allá de los tradicionales instrumentos de la "democracia de los ciudadanos" que el contenido constitucional buscaba asegurar como vía para la realización de su igualdad sustancial (art.3). Y esta vía se refería a la formación de una cultura del "contrapoder" y de la "resistencia democrática", junto a una cultura de los "derechos de libertad" cuyo desarrollo se quería confiar,

\footnotetext{
20 Ivi, pp.14 ss.

${ }^{21}$ Ivi, p. 309.

22 Cfr. L. Nivarra, Ipotesi sul diritto privato e $i$ suoi anni '70, en Id. (ed.) Gli anni '70 del diritto privato, Milano, 2008 , pp. 5,8, n. 7 .
} 
Alessandro Somma - A propósito del proceso, la democracia participativa y el rol de los medios de comunicación

en primera medida, a la acción de las asociaciones sindicales (art.39 s) y partidarias (art. 49) ${ }^{23}$.

No obstante, en los años 70 el rol de las cortes comienza a asumir relevancia. En esa época se genera una invitación a desarrollar un "uso alternativo del derecho burgués"; alternativo en cuanto dirigido a "configurar instrumentos de defensa de las libertades de las clases trabajadoras" 24 . Una invitación que evidentemente no abandonaba el recurso al contenido constitucional que, de hecho, habría debido realizarse por medio de la acción de las cortes, las cuales se juntarían con el grupo de sujetos encargados de contribuir a la vía constitucional hacia el socialismo ${ }^{25}$.

Sin duda, el uso alternativo del derecho era un uso militante; pero no lo era menos de aquel uso que se invocaba para su superación: ambos se obtenían a partir de una interpretación parcializada de los textos normativos, ciertamente inevitable en razón del desarrollo del papel asumido por el intérprete. Es decir, las cortes debían abandonar su función de meras mediadoras del contraste entre intereses diferentes y, así, contribuir para que emergieran las contradicciones inherentes a la relación entre capital y trabajo ${ }^{26}$.

Todo esto debe ser entendido como el resultado natural del desarrollo de las sociedades capitalistas, que exigen crecientes intervenciones estatales destinadas a dirigir la función ordenadora del mercado; intervenciones que determinan, a su vez, una creciente intervención de la sociedad civil en la producción de los textos normativos para, así, articular las finalidades indicadas. Es este el sentido del pasaje de la mediación judicial, entendida de una mera administración "externa" de un orden discreto, a la mediación judicial concebida para "organizar las relaciones entre los agentes sociales" 27. Un pasaje que, además, se genera a partir de la constatación de que en el ordenamiento constitucional conviven "una legislación de clase" con principios "incompatibles con dicha naturaleza clasista, como la justicia, la libertad, la igualdad" 28 . Y respecto a una situación de este tipo, resultaban necesarias elecciones prácticas, que quizás se pueden ocultar, pero ciertamente

\footnotetext{
${ }^{23}$ U. Romagnoli, Il sistema económico nella costituzione, en AA. VV., La Costituzione economica, en Trattato di diritto commeciale e di diritto pubblico dell' economía, dir. por F. Galgano, Padova, 1977, vol. I, p.149.

24 P. Barcelona, Introduzione, en Id. (ed.), L'uso alternativo del diritto, Roma-Bari, 1973, vol. I, p.VI.

25 Para todos S. D'AlBergo, Portata e condizioni di un uso alternativo della costituzione, en Dem. e dir., 1973, 1, pp. 55 y ss.

26 A. DI MAJO, Proposte per un avvio di discorso teorico sull'uso alternativo del diritto privato, en P. BARCELLONA (ed.), L' uso alternativo, cit., p. 159.

27 P. BARCEllona, Ruolo del giudice e mutamenti sociali, en Dem. e dir., 1987, 1-2, pp. 67 y ss.

28 L. BASSO, Giustizia e potere. La lunga via al socialismo, en Quale giustizia, 1971, p.652.
} 
Alessandro Somma - A propósito del proceso, la democracia participativa y el rol de los medios de comunicación

inevitables, ni siquiera por medio de un llamado a la supuesta cultura del tercer poder.

Los problemas podían surgir debido a la absoluta centralidad atribuida a la relación, o, mejor, a la contradicción, entre capital y trabajo, invocada como punto de referencia a partir del cual articular el uso alternativo del derecho. Todo en línea con la identificación de la democracia de los trabajadores como modelo llamado a nutrir, en modo más o menos penetrante, la democracia de los ciudadanos.

La paridad sustancial era tal, en cuanto fuente de una obligación de intervención de los poderes públicos, llamados a producir emancipación individual por medio de la ponderación de la debilidad social con la fuerza jurídica. Una intervención que partía, por ende, de la promoción de la solidaridad en las relaciones entre individuos y entre individuos y poderes públicos, entendida como reequilibrio entre las posiciones de los participantes en el conflicto social y no como imposición de la finalidad del sistema ${ }^{29}$.

En sustancia, la centralidad que se atribuida a las relaciones entre capital y trabajo permitía afirmar que la redistribución de la riqueza era el aspecto que principalmente se debía considerar en el esfuerzo de producir emancipación, indicando que esto requería medidas publicistas y privatistas de conformación de los comportamientos individuales en el ámbito de las relaciones de mercado. $Y$, por cierto, la centralidad de estas últimas, y su lectura en términos exclusivamente clasistas, terminaba por alterar la forma de entender la paridad sustancial y sus finalidades emancipadoras. Estas últimas imponían, de por sí, la valoración del conflicto social tout court y la solidaridad necesaria para realizar la paridad sustancial entre los participantes en el conflicto; mientras la perspectiva cultivada durante los años '70 terminaba por privilegiar el conflicto de clase y la solidaridad hacia las categorías débiles, identificadas a partir de las dinámicas del conflicto, ignorando, de este modo, todas las dinámicas redistributivas diferentes de aquellas mediadas por la posición asumida en el sistema productivo.

Para valorizar posiciones que se individualizan prescindiendo del conflicto de clase, como, por ejemplo, aquellas relativas a las relaciones de consumo y a las instancias relativas a la identidad diferentes de aquellas mediadas por la relación entre capital y trabajo, era necesario recurrir a otras tesis que en la época fueron criticadas o que lo serían a partir de entonces: las tesis de la

${ }_{29}$ Cfr. A. Somma, Alle radici del diritto privato europeo. Giustizia sociale, solidarietà e conflitto nell'ordine propietario, en Riv. crit. dir. priv., 2010, pp. 39 y ss. 
Alessandro Somma - A propósito del proceso, la democracia participativa y el rol de los medios de comunicación

sociología de los roles o de la cultura postmoderna. Y creemos precisamente que sea posible obtener esto por medio de las formas de diálogo entre cortes y sociedad; aspecto del que nos ocuparemos posteriormente.

\section{PROCESO Y ROL DEL INTÉRPRETE ENTRE CONSCIENCIA DEL JUEZ Y DIÁLOGO SOCIAL}

Regresamos por un momento a las conclusiones del congreso de GARDONE y, en particular, a la distinción entre orientación política general o constitucional y orientación política contingente: el primero correspondería a la magistratura y el segundo al parlamento y al ejecutivo.

Es fácil constatar que la verificación de la compatibilidad de una disposición con la orientación política constitucional que activa la competencia del juez, a diferencia de aquella que concierne la orientación política contingente, presupone la atribución de un significado a la disposición objeto de verificación, así como al texto constitucional usado como parámetro. $\mathrm{Y}$ en ambos casos es difícil afirmar que no hay un aporte creativo del juez: si el intérprete no es la boca de la ley, sino que, de hecho, es fuente sustancial del derecho, este atribuye relevancia política autónoma a todos los aspectos conexos con la formulación de preceptos destinados a resolver la controversia.

Dicho en otras palabras, si ya era claro que el sistema de fuentes no tenía más el aspecto, más o menos, reasegurador que predecía la esquematización contenida en las disposiciones preliminares del código civil (art.1), lo mismo sucedía con la interpretación de la ley, que se convirtió en una actividad cada vez menos describible recurriendo a la lógica formal (art.12). Esto se obtiene a partir de la constatación según la cual el ordenamiento comprendía, además de los valores constitucionales, microsistemas normativos destinados a privar de contenido a las codificaciones heredadas del pasado ${ }^{30}$ y a las fórmulas legislativas amplias contenidas en textos de época fascista, para, de este modo, poder adscribirles nuevos contenidos ${ }^{31}$. Y esto exigía la necesidad de repensar la teoría de la interpretación según esquemas anticipados por el debate que se presentó entre los filósofos del derecho en el curso de los años $60^{32}$ : es decir, prescindir de la acostumbrada contraposición entre interpretación formalista y antiformalista del derecho, ambas destinadas a confundirse en el ámbito de un sistema cuyo carácter polivalente ya era estructural ${ }^{33}$.

\footnotetext{
${ }^{30}$ N. IRTI, L' età della decodificazione, Milano, 1979, pp. 22, 41 y ss.

31 S. RODOTÀ, Ideologie e tecniche della reforma del diritto civile, en Riv. dir. comm., 1967, 1, pp. 83 y ss.

32 Cfr. P. Costa, L'alternativa presa sul serio, en Dem. e dir., 1987, 1-2, pp.19 y s.

33 P. BARCELlonA, Formazione e sviuppo del diritto privato moderno, Napoli, 1987, p. 114.
} 
Alessandro Somma - A propósito del proceso, la democracia participativa y el rol de los medios de comunicación

En realidad, reflexiones de este tipo estuvieron representadas durante el desarrollo del congreso de GARDONE. El mismo Giusseppe MARANINI precisó que la "necesidad de una amplia contribución interpretativa y constructiva del juez del caso concreto es válida, no sólo bajo el perfil de la conformidad constitucional, sino bajo cualquier otro perfil". Y esto porque, con las palabras del conocido juez de la Corte Suprema estadounidense, Benjamin CARDOZO, si también "se habla a menudo de la interpretación como si no fuese otra cosa que la búsqueda y el descubrimiento de una intención", en realidad esta concierne poco a "la búsqueda del significado latente del derecho positivo": "hay lagunas que colmar, dudas y ambigüedad que aclarar, hay problemas e injusticias que mitigar o, incluso eliminar" 34 .

A este punto MARANINI abandona el traje de innovador o, al máximo, de contestatario, para asumir el traje de paladín de los fundamentos tradicionales de la cultura liberal. La orientación política en la que el juez debe fundamentar su decisión es, en efecto, aquella que madura en la intimidad de su consciencia. EL juez está llamado, de un lado, a la "conciliación del derecho con la justicia"; pero, del otro, a hacerlo como resultado de un "libre e insondable proceso que madura en la profundidad del yo". Y si tal proceder no genera problemas de certeza del derecho, es sólo debido a la "vigilante conciencia del entero cuerpo judicial" ${ }^{\prime 3}$

De esta forma, una posición sin duda de avanzada, como es aquella dirigida a reivindicar el necesario valor político de la actividad del juez, termina por perder su carga innovadora, en cuanto confía a la conciencia individual y a la cultura de una clase la competencia exclusiva para determinar la validez de la actividad del juez. De una posición de apertura, necesaria para reservar para la magistratura el papel correspondiente al valor de decidir, se pasa a una posición de clausura según la cual decidir se convierte en una especie de hecho privado, o eventualmente institucional, pero siempre, al final, un hecho exclusivo.

Dicho de otra manera, le hace falta a la perspectiva liberal prestar atención al diálogo entre poderes y sociedad, que evidentemente presupone una visión de los primeros como eventualmente autónomos e independientes. Y le hace falta para reforzar la posición de los primeros en dicho diálogo, pero no para impedir su desarrollo.

\footnotetext{
${ }^{34}$ G. MARANINI, Funzione giurisprudenziale, cit., p. 21.

35 Ivi, pp. 25, 31.
} 
Alessandro Somma - A propósito del proceso, la democracia participativa y el rol de los medios de comunicación

La crítica de este aspecto de la cultura liberal fue típica en los años ' 70 . Sin embargo, esta se combinaba con una lectura de la convivencia social con una tendencia clasista que, por consiguiente, conducía a privilegiar el diálogo entre sujetos individuales en razón de su posición en el ámbito de las relaciones entre capital y trabajo. Y esto alteraba los términos del diálogo entre poderes y sociedad, limitado por una concepción selectiva de la paridad sustancial en relación con la individualización de las posiciones de debilidad social que se contrastaban con la atribución de la fuerza jurídica.

\section{SIGUE: CUÁNDO Y CÓMO DIALOGAR}

Al criticar la posición de MARANINI, seguramente no se pretende ignorar las exigencias que resultan patrocinadas por su punto de observación, todas relativas a la necesidad fundamental de defender la autonomía interna y externa de los jueces. Con esta crítica, simplemente, se quiere indicar que los mecanismos decisionales deben ser inteligibles, y esto resulta claramente limitado cuando se les convierte en un hecho privado o elitista; o, de todas formas, cuando son descritos como tales. Una visión de este tipo conduce necesariamente a desarrollar concepciones de la democracia como una cuestión de los técnicos o de los tecnócratas, según cánones considerados ahora como típicos de la postdemocracia, que convierten a la participación en el diálogo social en una cuestión "manipulada, pasiva y evanescente"36. Una visión principalmente incapaz de percibir la convivencia social como hecho político, o bien, como situación que se pueda plasmar más allá del mero perfil de su correcto funcionamiento desde el punto de vista técnico.

Ahora regresamos al rol del juez en el proceso y, entonces, al rol del tercer poder en la producción de las reglas de convivencia social. Seguramente, al juez le puede ocurrir que decide condicionado por mecanismos de pertenencia de clase. Del mismo modo, seguramente puede suceder que valora los comportamientos con base en las máximas de la experiencia: por ejemplo, teniendo en cuenta la debilidad o, en cambio, la fuerza estructural de los asociados involucrados en la controversia procesal o, eventualmente, teniendo en cuenta la identidad de estos últimos. Como sostiene Maranini, evocando el realismo jurídico, todo esto es inevitable; sin embargo, ello debe suceder de forma abierta, en medio del diálogo social. El ocultamiento de estos fenómenos genera debilidad, perdida de fuerza del tercer poder como contralor del poder legislativo, del poder ejecutivo y, por cierto, del poder económico; poder, este último, que actualmente se impuso sobre el poder

${ }_{36}$ C. CRouch, Postdemocrazia, Roma-Bari, 2003, p. 28. 
Alessandro Somma - A propósito del proceso, la democracia participativa y el rol de los medios de comunicación

político; pero que, en su momento, no fue contemplado por la tripartición clásica, formulada como respuesta a una preocupación por enfrentar el poder soberano.

En otras palabras, el diálogo social no es relevante solo por su contenido, que, de todas formas, debe estar orientado a la ejecución de preceptos en línea con el orden constitucional. El diálogo social, también, y sobre todo, es relevante debido a la posibilidad de que el mismo se desarrolle libre y públicamente, no desde el punto de vista de la sintonía, o no, de quien decide con el sentir común, sino, más bien, desde el punto de vista de la posibilidad de percibir sus articulaciones y su relevancia como momento de emersión del proceso decisional.

En suma, el diálogo social no desestabiliza un orden constituido; es, más bien, el reconocimiento de que el orden siempre se está constituyendo; obviamente en el respeto de algunos puntos estáticos: principalmente, aquellos relativos a la modalidad de desarrollo del diálogo y a la autonomía de quien hace parte del diálogo.

De este modo, la función del diálogo social no es, necesariamente, el reconocimiento del perfil de la publicidad del proceso y, en particular, de las audiencias. Esto último busca, principalmente, llevar a cabo un control de la decisión específica, de la prueba de los hechos objeto de la controversia, de su efectivo acaecimiento, de las reglas relativas a su reconstrucción ${ }^{37}$. Esta forma de control es la que precisamente crea muchos de los problemas generados por la atención mediática a las controversias procesales, perfil del que nos ocuparemos más adelante.

Diferente es el diálogo social concerniente a los presupuestos de la decisión $\mathrm{y}$, entonces, diferente es la forma como se configuran los instrumentos sobre los cuales el juez fundamenta su propio convencimiento. El diálogo busca la emersión de las motivaciones y las diferentes orientaciones sobre los aspectos más importantes de la vida social; el dialogo ayuda a completar la llamada democracia de los ciudadanos, siguiendo el surco de todos los aspectos relativos al principio de la paridad sustancial: el dialogo finalmente entendido más allá de los límites implícitos evocados por una democracia de los trabajadores.

\footnotetext{
37 A la publicidad como "elemento crucial en la valoración de la equidad de un proceso" recientemente la Corte Europea de Derechos Humanos ha hecho referencia en el caso Bongiorno v. Italia (sent. 5 de enero de 2010).
} 
Alessandro Somma - A propósito del proceso, la democracia participativa y el rol de los medios de comunicación

Por este motivo, el diálogo es apto en aquellas controversias procesales donde la relación entre el juicio y el sentir común responde a un interés general en la evolución del ordenamiento, donde se percibe que hay algo en juego más allá de la específica controversia y donde se enfrentan puntos de vista alternativos alrededor de los más importantes aspectos de la convivencia social. Controversias como esas muchas que acompañan la crónica judicial y política de nuestro tiempo, donde se discute de derechos civiles (regulación sobre los confines de la vida) derechos políticos y calidad de la democracia (represión de la corrupción), derechos sociales (prevención de los accidentes de trabajo), derechos de tercera generación (protección del ambiente), derechos económicos (represión de las estafas que vulneran a los consumidores), valores cuyo privilegio se impone por parte de la posmodernidad (pluralismo y multiculturalismo).

Es por esto que, en cambio, el diálogo social no es apto en aquellas controversias capaces de despertar y satisfacer la curiosidad, a menudo morbosa típica de un público constituido por telespectadores, más que por ciudadanos.

\section{PROCESO Y MEDIOS DE COMUNICACIÓN: LAS LECCIONES DE TORINO}

Como ya se puede intuir, el diálogo social que nace de una controversia procesal no es un hecho espontáneo o natural, sobre todo porque presupone que haya información sobre la controversia y sus múltiples lecturas. Lo anterior pone en el centro de atención el rol de los medios de comunicación $\mathrm{y}$, entonces, de la relación entre el tercer y el cuarto poder.

La relación es relevante, sobre todo, para la coordinación entre, de un parte, la libertad de prensa y libertad de expresión y, de otra parte, la correcta e imparcial administración de la justicia. Esta coordinación es sin duda relevante al momento de valorar la relación entre magistratura y medios de comunicación ${ }^{38}$; valoración a la cual se ha dedicado, en particular, la jurisprudencia de la Corte Europea de Derechos del Hombre ${ }^{39}$.

A nosotros, en cambio, nos interesa otro aspecto: la función de los medios de comunicación como vehículos idóneos para el desarrollo del diálogo social

\footnotetext{
38 Por último G. RESTA, trial by Madia as Legal Problem. A comparative analysis, Roma, 2008, y Id., I nuovi oracoli della giustizia: processi mediatici e laicità del diritto, en Riv. trim. dir. r proc. Civ., 2010, pp. 127 ss.

39 Con referencia a los arts. 6 y 10 de la Convención europea de derechos del hombre: Cfr. M. CHIAVARIO, I rapporti giustizia media nella giurisprudenza della Corte europea dei diritti dell'uomo, en Foro it., 2000, V, cc. 209 ss.
} 
Alessandro Somma - A propósito del proceso, la democracia participativa y el rol de los medios de comunicación

y, entonces, de informaciones y valoraciones de interés para el ciudadano, más que para el telespectador.

Evidentemente, este aspecto no es nuevo; fue tratado por parte de la Asociación Nacional de Magistrados, particularmente durante el congreso realizado en Torino en el año 1972. La elección del tema tenía en cuenta una sensibilidad entonces difundida: precisamente en aquellos años el desarrollo de las emisoras locales libres ${ }^{40}$ suscitaba el problema de la información plural. Todo esto en un sistema aún dominado por la prensa; pero dirigido hacia una crisis que se habría dramatizado con el paso del tiempo: la crisis provocada por la caída del mercado publicitario y por la competencia de la televisión.

El volumen que recopila las conferencias del congreso fue introducido por Nicoló LIPARI, reconocido estudioso del derecho, extraño al mundo de la magistratura, aunque no ajeno al mundo de la política: poco tiempo después fue nombrado miembro del consejo de administración de la RAI e inmediatamente después senador en representación de la Democracia Cristiana.

LIPARI analiza el tema de la relación entre el tercer y el cuarto poder a partir del tema de la visión de las instituciones y de las relaciones institucionales, afrontando, esta última relación, a partir de consideraciones similares a aquellas indicadas en relación con la distinción entre la consciencia individual y el diálogo social del juez. Es decir, se quiere evitar la discusión sobre la relación entre ambos poderes alegando una "inútil mística de los roles" $\mathrm{y}$, entonces, se "asume el hombre como punto de referencia objetivo, en cambio de asumirlo como sujeto de la experiencia social, organizada y gestionada por algunos poderes". De este modo, se termina por entender la información y la administración de la justicia como "hechos independientes, en abstracto destinados al crecimiento del hombre, pero extraños a su participación activa". Es precisamente privilegiando este punto de vista como se alimenta "la opinión de quien identifica en la administración de la justicia una forma de transmisión de valores elaborados más allá de la experiencia de sus destinatarios", así como "la opinión de quien ve en los medios de comunicación un abastecimiento de noticias y mensajes elaborados por súbditos y consumidores" 41 .

\footnotetext{
40 Primero obstaculizado con el d.p.r. del 29 de marzo de 1973 n. 156 y posteriomente incentivado por decisiones de la Corte Constitucional (sentencia del 28 de julio 1976 n. 202).

${ }^{41}$ N. LIPARI, Introduzione, en Id. (ed.), Giustizia e informazione. Atti del $15^{\circ}$ congresso dell'Associazione nazionale magistrati, Roma-Bari, 1975, pp. VII s y p. XI.
} 
Alessandro Somma - A propósito del proceso, la democracia participativa y el rol de los medios de comunicación

También es significativa la referencia a la libertad y multiplicidad de la información combinándolas con los valores de la autonomía y la independencia de la magistratura. Lo anterior equivale a afirmar que solo la información libre y plural es capaz de producir un diálogo social libre y plural. Y solo bajo estas condiciones el juez podrá contrastar los condicionamientos ocultos en su operar, aquellos reconducibles a su horizonte de valores, exactamente como las exigencias externas, y asumir así "una responsabilidad difusa frente a la colectividad en su conjunto". Para esto es necesario "no sólo admitir, sino estimular el debate público sobre los actos concretos de administración de la justicia" 42 .

Las principales conferencias presentadas durante el Congreso de Torino en gran parte se ocuparon de estos aspectos, todo ellos sintetizados bajo la idea según la cual el derecho a la información es el derecho a entender, no solo bajo la perspectiva liberal tradicional, sino bajo la perspectiva radicada en el texto constitucional. Es decir, el derecho a la información es un "derecho a participar", un "insustituible instrumento para asegurar la participación de los ciudadanos en la gestión de la cosa pública": no es un mero "derecho de independencia" sino un derecho que está dirigido "a garantizar la protección del individuo frente al poder" ${ }^{\prime 3}$.

Un rasgo común de todas las conferencias es la importancia dada del nexo inescindible entre, de un lado, la libertad y el pluralismo de la información y, del otro, la autonomía de la magistratura: ambos, de este modo, al servicio de un diálogo social productivo de participación democrática en la cuestión procesal.

A este punto, resulta central la definición de las líneas de intervención estatal que, en un sistema del cual ya nadie afirma la capacidad de auto-regularse, deben proteger la libertad y el pluralismo de información, considerados como valores de importancia de primer orden. Y, evidentemente, la intervención estatal debe realizarse con instrumentos de derecho público ${ }^{44}$; pero, también, con instrumentos de derecho privado, siendo relevante el conglomerado propietario de las entidades que están dirigidas por aquellos que confeccionan la información.

Así, el ordenamiento debe ocuparse de la propiedad de las "empresas responsables de la gestión" de los medios de información, que no puede

\footnotetext{
${ }^{42}$ Ivi, p. XVI.

43 G. LUMIA, L'informazione tra diritto e democracia, en N. LIPARI (ed.), Giustizia e informazione, cit., p. 66.

44 Por ejemplo, A. BARBera, Sub Art. 2, en Commentario della Costituzione, G. BRANCA (ed.), Bologna-Roma, 1975, pp. 72 ss.
} 
Alessandro Somma - A propósito del proceso, la democracia participativa y el rol de los medios de comunicación

sostenerse por medio del tradicional estatuto propietario, ni tampoco por aquel reformulado en sentido intervencionista para, sin embargo, defender la eficiencia económica de aquellas entidades. Se necesitarán intervenciones inspiradas por otras mecanismos, como aquellos dirigidos a "potenciar la autonomía" de los dependientes de las empresas de información, asegurándoles la "facultad de control colectivo sobre los movimientos financieros y de guía en general de la empresa" 45 .

\section{PROCESO Y DEMOCRACIA PARTICIPATIVA EN LA SOCIEDAD DE LA INFORMACIÓN}

Si la magistratura, en consecuencia, contribuye a definir la dirección política (general o contingente), es necesario crear las condiciones para que ello suceda de forma transparente y participada. Así se hace efectivo el principio de paridad sustancial entre los asociados, fundamento de la democracia participativa e instrumento de emancipación que no está mediado por puntos de observación limitados. De aquí el interés por el diálogo social entre jueces y sociedad y por el espacio público en que ese se presenta: el perímetro diseñado para la acción de los medios de información dentro de los cuales se configura la opinión pública ${ }^{46}$.

Ciertamente, en el momento en el cual esto se hace posible, también una información libre y plural puede alterar el diálogo social, en particular, promoviendo el interés morboso en los aspectos específicos de la controversia procesal, más que en los grandes temas de la convivencia social que emergen como consecuencia del caso específico. Tanto es así que se ha difundido el juicio sobre la mediatización de los procesos, formulado, a decir verdad, en términos muy "drásticos" ${ }^{47}$, según el cual los medios de comunicación alimentan "una competencia para la puesta en escena de la democracia": "despiertan el sueño de la democracia directa, es decir, el sueño de un acceso a la verdad liberada de cualquier mediación procesal", que "elude la regla para buscar directamente la sanción de la opinión pública" 48 .

Un juicio de este tipo no parece ciertamente infundado si se tienen en cuenta muchas de las corrientes prácticas de cobertura mediática de los procesos. Así como no está infundada la acusación según la cual la mediatización puede

\footnotetext{
${ }^{45}$ G. SFORZA, Libertà, pubblicità e segreto, en N. Lipari (ed.), Giustizia e informazione, cit., p. 81. También G. Verde, Informazione nell'iniciativa processuale, segreto e dissenso, ivi, pp. 138 ss.

46 Cfr. A. Somma, When law goes pop (2). La rappresentanza massmediatica del diritto, en Pol. dir., 2005, pp. 481 ss. Por último también B. Friedman, The Will of the People. How Public Opinion Has Influenced the Supreme Court and Shaped the Meaning of the Costitution, New York, 2009.

47 E. Bruti Liberati, Prefazione, en A. GARAPON, I custodi dei diritti, cit., p. 10.

48 A. GARAPON, I custodi dei diritti, cit. p. 59.
} 
Alessandro Somma - A propósito del proceso, la democracia participativa y el rol de los medios de comunicación

inducir una valoración acerca del funcionamiento de la justicia expresada en términos de eficiencia económica, en cuanto tal mucho más sensible a la lógica de la ganancia que a aquella de la afirmación de los valores supremos ${ }^{49}$.

Todo ello mientras los riesgos de manipulación relacionados con la mediación de los procesos se multiplican como consecuencia del uso de la imagen como forma de comunicación ${ }^{50}$ : asistimos desde tiempo atrás a lo que ha sido considerado como un iconic turn, fase que cierra o, al menos, pone en segundo plano, los años del linguistic turn ${ }^{51}$. Este es, de todas formas, el modo común de comunicar, no por casualidad elegido desde el ayer como terreno específico de investigación filosófico-hermenéutico ${ }^{52}$ y que ha conducido a reconocer a la imagen como instrumento autónomo de conocimiento utilizado por la mente humana ${ }^{53}$.

Se suma, además, -y esto es bien sabido- la transformación en el modo de comunicar inducida por la difusión del internet, hoy en día el principal competidor del medio televisivo en la difusión de la información. Y esto conlleva, sin duda, como sucede con la comunicación por imágenes, a la espectacularización de los mensajes transmitidos y a la banalización y a la manipulación de los significados, en nuestro caso inducidas, también, por la necesidad de disolver los tecnicismos del lenguaje jurídico.

Este es, por cierto, el espacio público dentro del cual necesariamente se presenta el diálogo sobre las controversias procesales. Un espacio sin duda condicionado por carencias en el plano de la multiplicidad y libertad de los medios de comunicación; carencias que con el pasar del tiempo parecen, en algunos aspectos, más crónicas ${ }^{54}$. Y, sin embargo, no es necesario intercambiar la patología de un sistema nacional con la fisiología del modelo en el cual se inspira: la sociedad de la información, o sociedad posindustrial, caracterizada por la tercerización del sistema productivo y, por consiguiente, por el desarrollo de la economía del conocimiento: la economía en la cual el conocimiento, de instrumento, se transforma en producto y, en cuanto tal, es manipulada ${ }^{55}$.

\footnotetext{
${ }^{49}$ Cfr. A. FusARO, Giustzia e mass media nella prospettiva del diritto comparato, en Iustitia, 2009, pp. 83 y ss, con referencias a recientes intervenciones del primer Presidente de la Corte de Casación y de la Autoridad para la garantía en las comunicaciones.

50 A. GARAPON, I custodi dei diritti, cit. p. 60.

51 Por ejemplo C. MAAR Y BURDA (eds.), Iconic turn. Die meue Macht der Bilder, Köln, 2004.

52 Para todos G. BoEHM, Die Wiederkehr der Bilder, en Id. (ed.), Was iste in Bild?, München, 1994, pp. 29 y ss.

53 M. JAY, The Denigration of Vision in Twentieth Century French Thought, Berkeley etc., 1993, p. 588.

54 I. Russo, Giustizia e informazione, en Quest. Giustizia, 2000, pp. 829 s.

55 Por ejemplo V. CODELUPPI, Il biocapitalismo. Verso lo sfruttamento integrale di corpi, cervelli ed emozioni, Torino, 2008, pp. 21 ss.
} 
Alessandro Somma - A propósito del proceso, la democracia participativa y el rol de los medios de comunicación

También el mercado que funciona según sus reglas -más que aquel caracterizado por patologías más o menos radicadas-principalmente en concurso con su creciente dimensión global, priva a la política del espacio necesario para asegurar, de un lado, la libertad y multiplicidad del cuarto poder $\mathrm{y}$, de otro lado, la autonomía e independencia del tercer poder. También esto constituye un resultado del proceso de americanización del derecho evocado al inicio de este trabajo, un proceso cada vez más dirigido a evitar la conformación de comportamientos individuales que tengan una finalidad diferente a aquella dirigida a la construcción de un mercado global.

Parece que no existe una seria alternativa a las actuales formas de información que, sin duda, deben ser repensadas y manejadas con atención y cuidado; pero que no pueden ser simplemente refutadas en cuanto vehículos de perversión del orden democrático. El diálogo social es un componente indispensable de aquel orden, y su supresión solo puede conducir a su mal funcionamiento. 